\title{
Transformation of Z-thiacloprid by three advanced oxidation processes: Kinetics, intermediates and the role of reactive species
}

\author{
Georgina Rózsa $^{\mathrm{a}, \mathrm{b}}$, Zsuzsanna Kozmér ${ }^{\mathrm{a}, \mathrm{b}}$, Tünde Alapi ${ }^{\mathrm{a}}$, Krisztina Schrantz ${ }^{\mathrm{a}, *}$, \\ Erzsébet Takács ${ }^{\mathrm{b}}$, László Wojnárovits ${ }^{\mathrm{b}}$ \\ a Department of Inorganic and Analytical Chemistry, University of Szeged, H-6720 Szeged, Dóm tér 7, Hungary \\ ${ }^{\mathrm{b}}$ Radiation Chemistry Department, Centre for Energy Research, Hungarian Academy of Sciences, H-1121 Budapest, Konkoly-Thege Miklós út 29-33, \\ Hungary
}

\section{A R T I C L E I N F O}

\section{Article history:}

Received 14 July 2016

Received in revised form 5 October 2016

Accepted 25 November 2016

Available online $\mathrm{xxx}$

\section{Keywords:}

Thiacloprid

AOPs

Hydroxyl radical

Hydrated electron

Intermediates

Electric energy per order

\begin{abstract}
A B S T R A C T
Three advanced oxidation processes (AOPs), heterogeneous photocatalysis, vacuum ultraviolet (VUV) photolysis and $\gamma$ radiolysis were used for the generation of reactive primary free radicals to induce the transformation of Z-thiacloprid in aqueous solution. The effects of dissolved oxygen and the initial concentration (from $10^{-6}$ to $10^{-4} \mathrm{~mol} \mathrm{~L}^{-1}$ ) were investigated. The initial reaction rates increased with the initial concentration of thiacloprid, both in oxygen saturated and oxygen free solutions. Dissolved oxygen had significant effect on the transformation rate only in case of heterogeneous photocatalysis. Three main intermediates and the E-thiachloprid were detected using all three methods. One of these intermediates could be related to the reaction with $\mathrm{e}_{\mathrm{aq}}{ }^{-}$, while the other two could be related to the ${ }^{\bullet} \mathrm{OH}$-initiated reactions. Heterogeneous photocatalysis showed the highest efficiency regarding the transformation of intermediates in presence of dissolved oxygen, while thiacloprid transformed with the highest initial reaction rate during VUV photolysis. However, according to the Electric energy per order $\left(E_{\mathrm{EO}}\right)$ data $\gamma$ radiolysis was found to be the economically most feasible method, requiring several orders of magnitude less energy than VUV photolysis and heterogeneous photocatalysis for reduction of the target compound concentration by one order of magnitude in a unit volume.
\end{abstract}

(C) 2016 Elsevier B.V. All rights reserved.

\section{Introduction}

Large number of methods have been suggested in the literature for the degradation of harmful organic molecules, for instance pesticide residues, in water and wastewater [1]. In these studies more and more attention is focused on the neonicotinoid family (imidacloprid, thiamethoxam, acetamiprid, clothianidin, dinotefuran, nitenpyram and thiacloprid), the fastest growing group among the insecticides. These compounds have long term impact on the ecosystem, especially they have harmful effects on bees, weakening their immune system, and increasing their sensitivity to pathogenic viruses [2]. The name neonicotinoids suggests similarity in the

\footnotetext{
* Corresponding author.

E-mail addresses: rozsa.georgina@chem.u-szeged.hu (G. Rózsa) kozmerzs@chem.u-szeged.hu (Z. Kozmér), alapi@chem.u-szeged.hu (T. Alapi), sranc@chem.u-szeged.hu (K. Schrantz),erzsebet.takacs@energia.mta.hu (E. Takács), wojnarovits.laszlo@energia.mta.hu (L. Wojnárovits).
}

chemical structure with nicotine and acetylcholine, for exerting their effects on the acetylcholine receptors [3].

One of the representative members of neonicotinoides is Z-thiacloprid (\{3-[(6-Chloropyridin-3-yl) methyl]-1,3-thiazolidin2 -ylidene\} cyanamide) (Fig. 1). It has very high stability and good solubility in water $\left(184 \mathrm{mg} \mathrm{L}^{-1}\right.$ at $\left.20^{\circ} \mathrm{C}\right)$ [4]. This compound can be accumulated in the environment through the trophic network [5], and therefore, it is detected in an increasing amount in surface waters.

Due to the three biologically active groups in its structure, chloropyridine and thiazolidine rings, and the cyanoimino group, thiacloprid is strongly toxic with lethal dose of $L D_{50}=444 \mathrm{mg} \mathrm{kg}^{-1}$ for rats. In agriculture it is used against sucking and chewing pests [6] in crops, such as rapeseed, sunflower, potatoes, apple, as well as for corn seed dressing. Stability tests showed that thiacloprid was less persistent in acidic solution, but in alkaline media, it was stable for about 30 days [7].

The decomposition of neonicotinoids has been examined by several advanced oxidation processes (AOP) [8]. Zbiljić et al. showed, that the removal of acetamiprid using photo-Fenton process is 


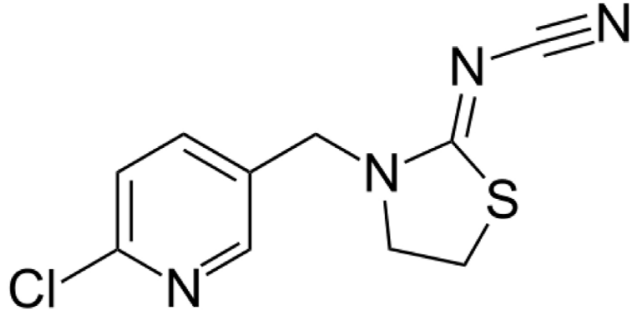

Fig. 1. Chemical structure of thiacloprid.

twice as effective ( $\sim 10 \mathrm{~min}$ ) as using Fenton processes only [9]. Imidacloprid transformation needed $\sim 60$ min using both Fenton and photo-Fenton processes combined with hydrodynamic cavitation [10]. Malato et al. reported that the degradation of imidacloprid using titanium dioxide $\left(\mathrm{TiO}_{2}\right)$ photocatalyst under UV-A irradiation is a relatively slow process $\left(\sim 0.61 \mathrm{mg} \mathrm{L}^{-1} \mathrm{~min}^{-1}\right)$ [11]. The photocatalytic degradation of imidacloprid, thiamethoxam and clothianidin on immobilised $\mathrm{TiO}_{2}$ has also been studied. Within $2 \mathrm{~h}$ of photocatalysis, all three neonicotinoids were degraded following first order kinetics [12]. Thiamethoxams' transformations were investigated also using UV photolysis, ozonation and their combinations [13]. The effect of dissolved ozone and ferric ions on the intermediates of thiacloprid formed during $\mathrm{TiO}_{2}$-based heterogeneous photocatalysis was investigated in suspensions [14-16] and using immobilized catalyst [17].

To our best knowledge no results have been published yet on the vacuum ultraviolet (VUV) photolysis and $\gamma$ radiolysis of thiacloprid.

To understand the mechanism of transformation of organic compounds, one of the most important steps is gathering information about the nature of reactions of the target compound with the reactive species generated by AOPs.

Among the AOP methods VUV photolysis and $\gamma$ radiolysis are good candidates to investigate the role of hydroxyl radical $(\bullet \mathrm{OH})$ and hydrated electron $\left(\mathrm{e}_{\mathrm{aq}}{ }^{-}\right)$in the degradation of organic molecules. In contrast to the VUV photolysis, during $\gamma$ radiolysis in dissolved oxygen (DO) free solutions beside the $\bullet \mathrm{OH}$, the role of the $\mathrm{e}_{\mathrm{aq}}{ }^{-}$is also relevant. Although the basic mechanism of the $\mathrm{TiO}_{2}$-based heterogeneous photocatalysis had been investigated by a great number of research groups $[18,19]$ the identities of reactive species are still under intensive discussion. During the illumination of photocatalysts by UV light $\left(\lambda_{\max }=365 \mathrm{~nm}\right.$ for $\left.\mathrm{TiO}_{2}\right)$ valence band holes $\left(\mathrm{h}^{+}\right.$, a localized oxidizing state) and conduction band electrons $\left(\mathrm{e}^{-}\right)$form (Eq. (1)). The oxidation of organic solutes (OS) is assumed to take place directly by the surface hole, or through a - OH on the surface (Eq. (4)) formed in the reaction of the hole with a hydroxyl anion or water molecule (Eq. (2)). It is an open question if the OS can react directly with the $\mathrm{e}^{-}$at the surface of the catalyst. In the presence of DO its reaction with $\mathrm{e}^{-}$(Eq. (3)) produces superoxide radical anion $\left(\mathrm{O}_{2}{ }^{\bullet-}\right)$. In further reactions $\mathrm{O}_{2}{ }^{\bullet-}$ yields $\mathrm{H}_{2} \mathrm{O}_{2}$, which finally transforms into $\bullet \mathrm{OH}$ (Eq. (3), [19,20]).

$\mathrm{TiO}_{2}+$ UVphoton $_{\lambda}=365 \mathrm{~nm} \rightarrow \mathrm{e}^{-}+\mathrm{h}^{+}$

$\mathrm{h}^{+}+{ }^{-} \mathrm{OH}\left(\mathrm{H}_{2} \mathrm{O}\right) \rightarrow{ }^{\bullet} \mathrm{OH}_{\text {surf }}\left(\bullet \mathrm{OH}_{\text {surf }}+\mathrm{H}^{+}\right)$

$\mathrm{e}^{-}+\mathrm{O}_{2} \rightarrow \mathrm{O}_{2}^{\bullet-} \rightarrow \mathrm{HO}_{2}{ }^{\bullet} \rightarrow \mathrm{HO}_{2}^{-} \rightarrow \mathrm{H}_{2} \mathrm{O}_{2} \rightarrow 2^{\bullet} \mathrm{OH}$

$\mathrm{h}^{+}\left(\mathrm{or}^{\bullet} \mathrm{OH}_{\text {surf }}\right)+\mathrm{OS} \rightarrow$ oxidizedproducts

During the VUV photolysis of aqueous solutions, using a commercial $\mathrm{Xe}_{2}{ }^{*}$ excimer lamp $(\lambda=172 \mathrm{~nm})$, homolytic dissociation of water molecules results in ${ }^{\bullet} \mathrm{OH}$ and hydrogen radical $\left(\mathrm{H}^{\bullet}\right)$ with quantum yield of 0.42 (Eq. (5)) [21,22]. With low yield ionization also takes place. The so-called dry electron released in ionization may stabilize in the form of $\mathrm{e}_{\mathrm{aq}}{ }^{-}$(Eq. (6)) [22,23]:

$$
\begin{aligned}
& \mathrm{H}_{2} \mathrm{O}+\operatorname{VUVphoton}_{\lambda=172 \mathrm{~nm}} \rightarrow \mathrm{H}^{\bullet}+\cdot \mathrm{OH} \\
& \Phi_{172 \mathrm{~nm}}\left(\bullet \mathrm{OH}, \mathrm{H}^{\bullet}\right)=0.42 \\
& \mathrm{H}_{2} \mathrm{O}+\operatorname{VUVphoton}_{\lambda=172 \mathrm{~nm}} \rightarrow \mathrm{H}^{+}+\mathrm{e}_{\mathrm{aq}}{ }^{-}+\cdot \mathrm{OH} \\
& \Phi_{172 \mathrm{~nm}}\left(\mathrm{e}_{\mathrm{aq}^{-}}\right)<0.05
\end{aligned}
$$

In VUV photolysis at $172 \mathrm{~nm}$ the photons are absorbed in a very thin layer of a few $\mu \mathrm{m}$. In this reaction zone there is a strong competition between the reactions of reactive species $\left({ }^{\bullet} \mathrm{OH}\right.$ and $\left.\mathrm{H}^{\bullet}\right)$ with each other and with thiacloprid and its intermediates.

During $\boldsymbol{\gamma}$ radiolysis of aqueous solutions the decomposition of water molecules results in ${ }^{\bullet} \mathrm{OH}, \mathrm{e}_{\mathrm{aq}}{ }^{-}$and (in lower yield) $\mathrm{H}^{\bullet}$, as primary radicals (Eq. (7)) with yields (so-called $G$-values) of 0.280 , 0.280 and $0.062 \mu \mathrm{mol} \mathrm{J}^{-1}$, respectively [24,25].

$\mathrm{H}_{2} \mathrm{O}+$ yphoton $\rightarrow \cdot{ }^{\bullet} \mathrm{OH}+\mathrm{e}_{\mathrm{aq}}{ }^{-}\left(+\cdot{ }^{\bullet}\right)$

In the presence of DO the reductive primary species $\left(\mathrm{H}^{\bullet} / \mathrm{e}_{\mathrm{aq}}{ }^{-}\right)$ transform to less reactive hydroperoxyl radical/superoxide radical anion $\left(\mathrm{HO}_{2} \cdot / \mathrm{O}_{2}{ }^{\bullet-}\right)$ (Eqs. (8) and (9)) [26].

$$
\begin{array}{ll}
\bullet \mathrm{H}+\mathrm{O}_{2} \rightarrow \mathrm{HO}_{2}{ }^{\bullet} & k_{8}=1.2 \times 10^{10} \mathrm{~L} \mathrm{~mol}^{-1} \mathrm{~s}^{-1} \\
\mathrm{e}_{\mathrm{aq}}{ }^{-}+\mathrm{O}_{2} \rightarrow \mathrm{O}_{2} \cdot- & k_{9}=1.9 \times 10^{10} \mathrm{~L} \mathrm{~mol}^{-1} \mathrm{~s}^{-1}
\end{array}
$$

In heterogeneous photocatalysis, VUV photolysis and $\gamma$ radiolysis ' $\mathrm{OH}$ are assumed to play a key role in the pollutants' degradations, mainly in the presence of DO. However, their distributions in space are significantly different: i) in $\mathrm{TiO}_{2}$ photocatalysis the reactive species are on the catalyst surface, ii) in VUV photolysis they are produced close to the window, with inhomogenous distribution, and iii) in $\gamma$ radiolysis the reactive species, with the yields mentioned above, are more-or-less homogeneously distributed in the solution bulk.

Thiacloprid has three sensitive parts for the ${ }^{\bullet} \mathrm{OH}$-induced oxidation: 2-cloropyridine, thiazolidine and the cyanoimino part. Pyridine reacts with $\cdot \mathrm{OH}, \mathrm{e}_{\mathrm{aq}}{ }^{-}$and ${ }^{\bullet} \mathrm{H}$ with the rate constants of $3.0 \times 10^{9} \mathrm{~L} \mathrm{~mol}^{-1} \mathrm{~s}^{-1}, 7.7 \times 10^{9} \mathrm{~L} \mathrm{~mol}^{-1} \mathrm{~s}^{-1}$ [27] and $6.0 \times 10^{8} \mathrm{~L} \mathrm{~mol}^{-1} \mathrm{~s}^{-1}$ [28], respectively. $\bullet \mathrm{OH}$ reacts with nicotinic acid with rate constant of $5.6 \times 10^{9} \mathrm{~L} \mathrm{~mol}^{-1} \mathrm{~s}^{-1}$ [29]. Due to the electron withdrawing $\mathrm{Cl}$ substituent the rate constant of 2cloropyridine with ${ }^{\bullet} \mathrm{OH}\left(1.8 \times 10^{9} \mathrm{~L} \mathrm{~mol}^{-1} \mathrm{~s}^{-1}\right.$ [29] $)$ is smaller than that of pyridine. ${ }^{\bullet} \mathrm{OH}$ generally attacks the thioether groups also with rate constants of about $10^{9} \mathrm{~L} \mathrm{~mol}^{-1} \mathrm{~s}^{-1}$. The double bond in the cyanoimino part of the molecule may also be involved in reaction with this radical. In case of thiazolidine no data are available about its reactions with these primary radicals. Only one value of the ${ }^{\bullet} \mathrm{OH}$ rate constant with thiacloprid was determined using flash photolysis $\left(7.5 \times 10^{10} \mathrm{~L} \mathrm{~mol}^{-1} \mathrm{~s}^{-1}[30]\right.$, however this rate constant is unrealistic since it is half of an order of magnitude higher than the diffusion limited value). There is no information available about the reactions of neonicotonoid insecticides with $\mathrm{e}_{\mathrm{aq}}{ }^{-}$and $\mathrm{H}^{\bullet}$.

The aim of this work was the comparison of thiacloprid transformation using heterogeneous photocatalysis, VUV photolysis and $\gamma$ radiolysis in the presence and absence of DO, the study of the kinetic properties of thiacloprid reactions with the primary reactive species formed in these processes, and the identification of the intermediates formed during the applied treatments. The economic feasibility of the three methods was compared based on the Electrical energy per order $\left(\mathrm{E}_{\mathrm{EO}}\right)$. 

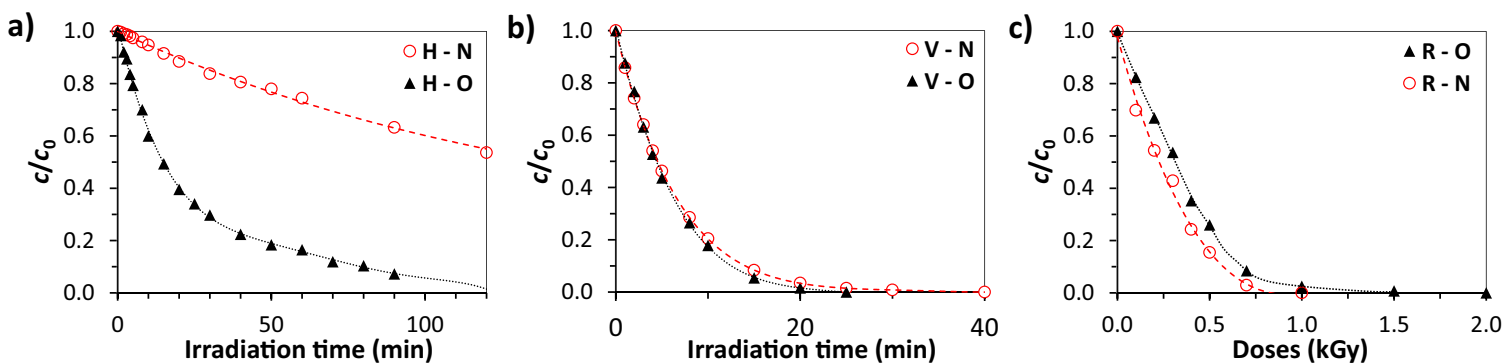

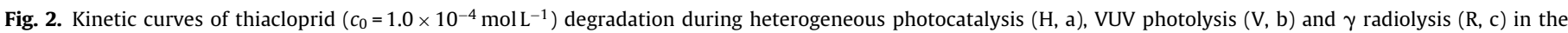
presence $(\boldsymbol{\Lambda})$ and absence $(\mathrm{O})$ of dissolved $\mathrm{O}_{2}$

a)

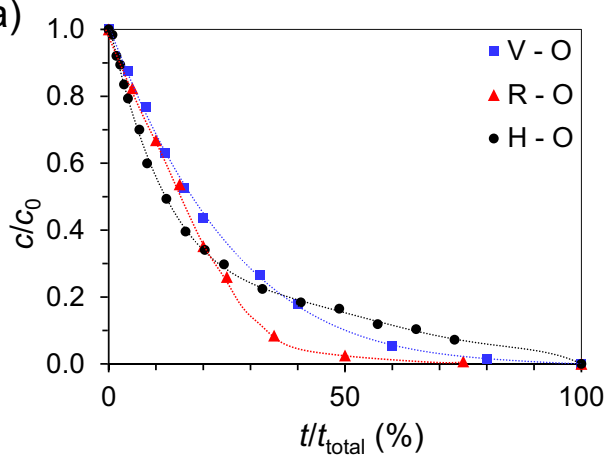

b)

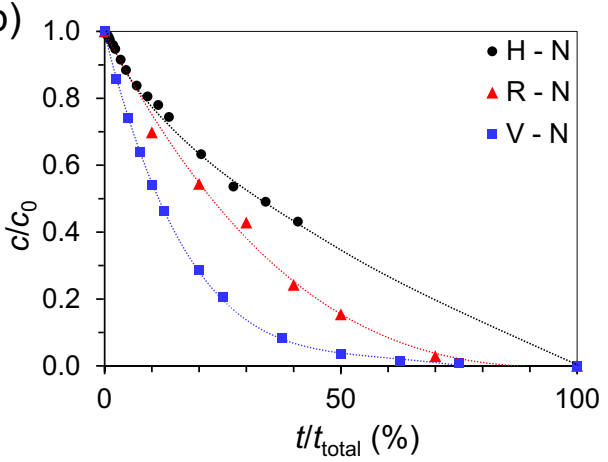

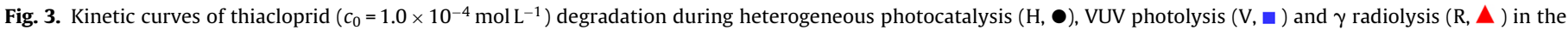
presence (a) and absence (b) of dissolved $\mathrm{O}_{2}$.

\section{Materials and methods}

\subsection{Materials and equipment}

In VUV photolytic and heterogeneous photocatalytic experiments $250 \mathrm{~mL}$ thiacloprid (Sigma-Aldrich, 99.9\%) solutions with initial concentrations $\left(c_{0}\right)$ of $1.0 \times 10^{-4}, 1.0 \times 10^{-5}$ and $1.0 \times 10^{-6} \mathrm{~mol} \mathrm{~L}^{-1}$, prepared in ultrapure MILLI-Q water (MILLIPORE Milli-Q Direct 8/16), were irradiated. In the photocatalytic experiments the $\mathrm{TiO}_{2}$ (Degussa P25, Evonik Aeroxide) concentration was $1.0 \mathrm{~g} \mathrm{~L}^{-1}$; the samples were centrifuged (Dragonlab D2012, $2 \mathrm{~min}, \mathrm{rpm}=15000$ ) and filtered with syringe filter (Sartorius Stedim, Ministart ${ }^{\circledR}$-plus, $\left.0.20 \mu \mathrm{m}\right)$ after irradiation, to remove the photocatalyst particles.

During the VUV photolysis and heterogeneous photocatalysis the solutions and suspensions were circulated $\left(375 \mathrm{~mL} \mathrm{~min}^{-1}\right)$ between the temperature controlled $\left(\mathrm{T}=25 \pm 0.5^{\circ} \mathrm{C}\right)$ reactor and the reservoir by a Heidolph Pump drive 5001 peristaltic pump. The solutions and suspensions in the tank were constantly stirred with a magnetic stirrer, while they were bubbled with $\mathrm{O}_{2}$ or $\mathrm{N}_{2}$ gas (Messer, $>99.5 \%$ purity) at a flow rate of $600 \mathrm{~mL} \mathrm{~min}^{-1}$. The injection of the gas was started $30 \mathrm{~min}$ before each experiment and was continued during the irradiation. For VUV photolysis a $20 \mathrm{~W} \mathrm{Xe}_{2}{ }^{*}$ excimer lamp (Radium Xeradex TM, dimensions: $180 \mathrm{~mm} \times 48 \mathrm{~mm}$ ) emitting at $172 \pm 14 \mathrm{~nm}$ was used. The photon flux, determined by methanol actinometry [31], was found to be $3.0 \times 10^{-6}$ mol $_{\text {photon }} \mathrm{s}^{-1}$. The heterogeneous photocatalysis was performed with a specific fluorescent UV lamp (GCL303T5/UVA, LighTech, Hungary, dimensions: $360 \mathrm{~mm} \times 30 \mathrm{~mm}$ ) emitting in the range of $300-400 \mathrm{~nm}$ with $\lambda_{\max }=365 \mathrm{~nm}$. The photon flux of the light source was $1.2 \times 10^{-5} \mathrm{~mol}_{\text {photon }} \mathrm{s}^{-1}$, determined by ferrioxalate actinometry [32].

In $\gamma$ radiolysis experiments the $5 \mathrm{~mL}$ ampoules with thiacloprid solution, prepared in ultrapure MILLI-Q water (ELGA option 4 ), were placed to equal distance from the ${ }^{60} \mathrm{Co}-\gamma$ source of an SSL-
01 panoramic type irradiator, to have a dose rate of $0.7 \mathrm{kGy} \mathrm{h}^{-1}$ $\left(700 \mathrm{~J} \mathrm{~kg}^{-1} \mathrm{~h}^{-1}\right)$. The solutions were irradiated in open ampoules or in sealed ampoules saturated with $\mathrm{N}_{2}$.

Measurements were repeated three times and in cases of VUV photolysis and $\gamma$ radiolysis the standard deviation of the obtained values was less than $\pm 5 \%$. In case of photocatalytic measurements the sample preparation (filtration) slightly increased this value (5-8\%).

\subsection{Analytical methods}

The absorption spectra of the treated samples were detected by spectrophotometry (Agilent 8453 or Agilent $1200,0.5 \mathrm{~cm}$ pathway). Z-thiacloprid and the formed intermediates were separated and detected by Agilent 1100 type HPLC equipped with diode array detector (DAD) and an Agilent G1956A quadrupole mass spectrometric (MS) detector. A LiChroCart ${ }^{\circledR}$ (250-4, RP-18, $\left.5 \mu \mathrm{m}\right)$ reverse-phase column was utilized for the separations. A mixture of methanol (70\%) and water (30\%) was used as eluent, at $0.6 \mathrm{~mL} \mathrm{~min}^{-1}$ flow rate and $25^{\circ} \mathrm{C} .20 \mu \mathrm{L}$ samples was analysed at $242 \mathrm{~nm}$ (absorption maximum of thiacloprid). The MS analysis was carried out in positive and negative ion modes, with an electrospray ionization source (ESI) using 70 and $90 \mathrm{~V}$ fragmentor voltages.

The determination of Z-thiacloprid concentration was based on the linear regression of calibration curve $\left(R^{2}=0.9995\right)$ presenting the integrated peak areas of the chromatograms measured by HPLC-DAD. Kinetic curves show the ratio of the actual and the initial Z-thiacloprid concentrations $\left(\mathrm{c} / \mathrm{c}_{0}, \mathrm{c}_{0}=1.0 \times 10^{-4} \mathrm{~mol} \mathrm{~L}^{-1}\right)$.

The transformation of Z-thiacloprid was characterized by the initial rate of degradation $\left(r_{0}\right)$, which was obtained from linear regression fits of the decay curves corresponding to $10 \%$ of transformation. 
a)
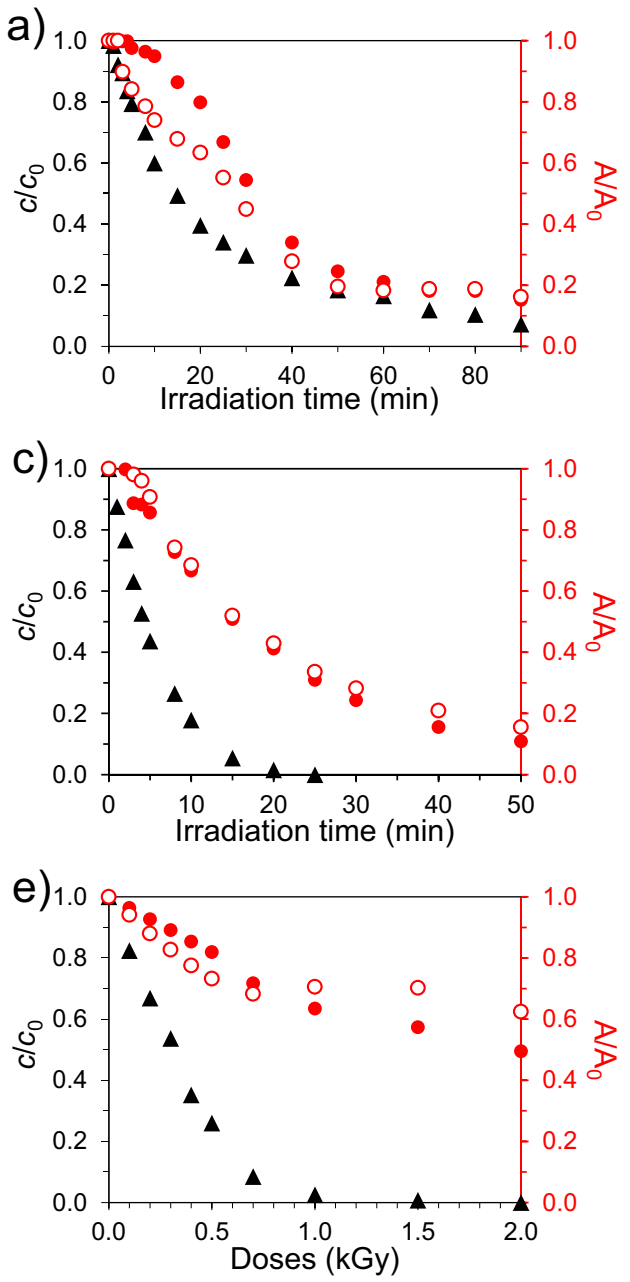

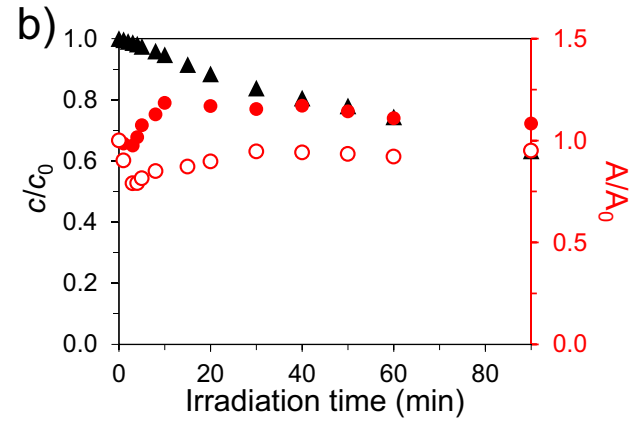

d) 1
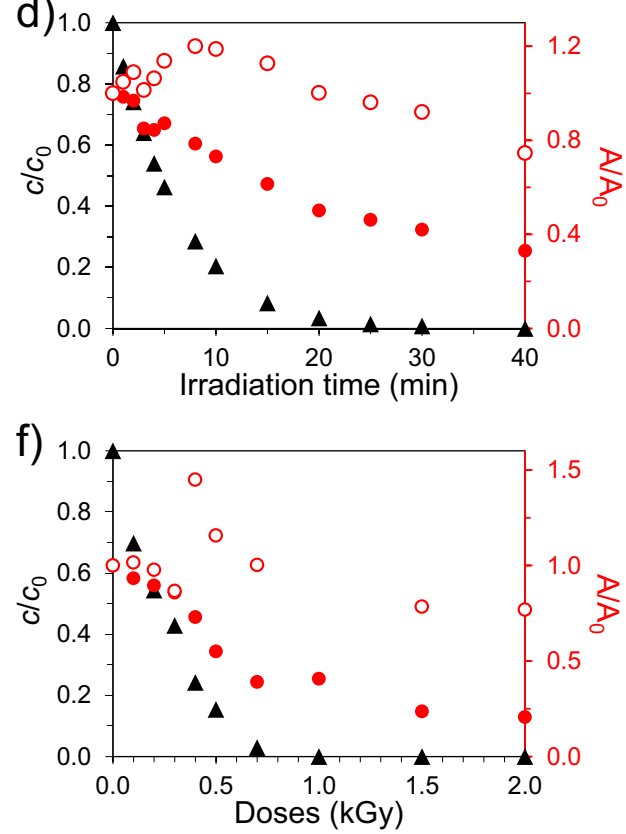

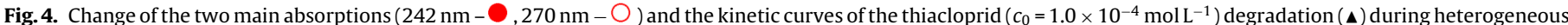
photocatalysis ( $a$ and b), VUV photolysis ( $c$ and d) and $\gamma$ radiolysis (e and f) in the presence (a, $c$ and e) and in the absence (b, d and f) of dissolved $\mathrm{O}_{2}$.

\section{Results and discussion}

\subsection{Degradation followed by UV-spectrophotometry}

The transformation of thiacloprid was first investigated by UVspectrophotometry between 200 and $350 \mathrm{~nm}$. In the UV spectrum of thiacloprid there is an absorption maximum at $242 \mathrm{~nm}$, and two shoulders around 220 and $270 \mathrm{~nm}$. In the UV spectrum of 2-chloropyridine the latter two bands also appear, being characteristic for the chloro-substituted aromatic ring. The strong absorption band with centre at $242 \mathrm{~nm}\left(\varepsilon_{\max }=18800 \mathrm{~mol} \mathrm{~L}^{-1} \mathrm{~cm}^{-1}\right)$ belongs to the 2-thiazolidinecyanamide part of the molecule. This absorbance maximum slightly shifts to lower wavelengths with the increase of the treatment time. The recorded spectra are presented in the Supplementary materials, in Fig. S1.

\subsection{Degradation kinetics of thiacloprid}

In Fig. 2 degradation kinetic curves of thiacloprid $\left(c_{0}=1.0 \times 10^{-4} \mathrm{~mol} \mathrm{~L}^{-1}\right)$ are shown in presence and absence of DO. The results show no significant difference in case of VUV photolysis, in spite of the fact that in presence of DO the recombination of the primary radicals $\left(\bullet \mathrm{OH}\right.$ and $\left.\bullet^{\bullet} \mathrm{H}\right)$ is hindered. Only slight increase of the transformation rate in case of radiolysis in absence of DO was observed, due to the presence of $\mathrm{e}_{\mathrm{aq}}{ }^{-}$. The similar reaction rate of $\mathrm{e}_{\mathrm{aq}}{ }^{-}$and the ${ }^{\bullet} \mathrm{OH}$ reactions in case of chloropyri- dine supports this observation [33]. In case of the heterogeneous photocatalysis without an effective electron scavenger, there is no possibility for any redox reaction at the surface, due to the favoured recombination of the photoinduced charges. Therefore in DO-free solution the role of the oxygen could be taken over by thiacloprid, consequently this creates a possibility for adsorbed thiacloprid to react both with the $\mathrm{h}^{+}$and $\mathrm{e}^{-}$. The difference in the transformation rates in presence and absence of DO can be explained by the difference in their concentration in solution $\left(2.5 \times 10^{-4} \mathrm{~mol} \mathrm{~L}^{-1}\right.$ (DO) and $1.0 \times 10^{-4} \mathrm{~mol} \mathrm{~L}^{-1}$ (thiacloprid)) and in the adsorbed amount of oxygen and thiacloprid. This is supported by the results presented in Fig. 2a.

The initial rates of degradation $\left(r_{0}\right)$ are shown in Table 1 . As expected, all the $r_{0}$ decreased significantly with the decrease of the initial concentration of thiacloprid. However, the reaction rate constants $(k)$ increased significantly. For heterogeneous photocatalysis, in presence of DO, this increase was observed only for smallest concentration. In VUV photolysis the $k$ values increased strongly and linearly with the decreasing thiacloprid concentration reflecting the availability of the ${ }^{\bullet} \mathrm{OH}$ for the organic molecules in the very thin reaction zone, both in presence and absence of DO. In $\gamma$ radiolysis reactions the $k$ increased significantly only in presence of DO, in the most diluted solution. This may partly be due to the higher ${ }^{\bullet} \mathrm{OH}$ stationary concentration at lower solute concentration. This increase was not observed in absence of DO. 
Table 1

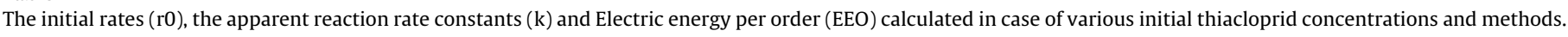

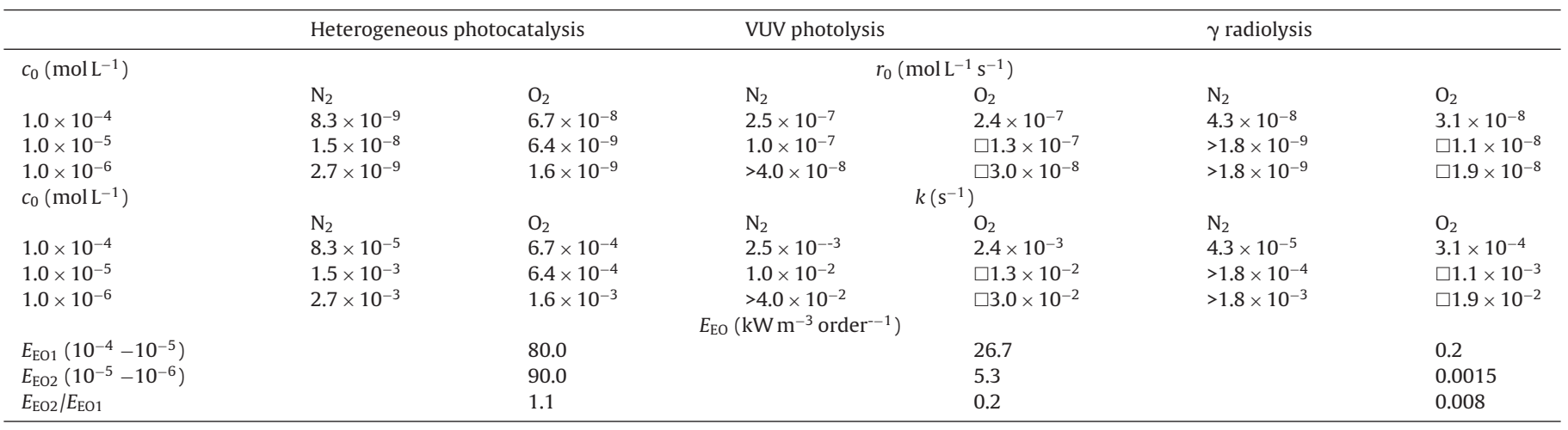

In Fig. 3 the methods are compared in presence and absence of DO. On the abscissa the time scale is normalized to the time needed for complete removal of thiacloprid ( $t_{\text {total }}$, during heterogeneous photocatalysis, VUV photolysis and $\gamma$ radiolysis in the presence and absence of DO: 120 and $440 \mathrm{~min}$ (estimated by the linear regression of the last 3 points); 25 and $25 \mathrm{~min} ; 1.5$ and $1.0 \mathrm{kGy}$, respectively). Although the value of $t_{\text {total }}$ is arbitrary, this way of plotting helps the comparison of the kinetic curves. Until $\sim 20 \% t / t_{\text {total }}$ sharp decrease was observed in all three methods. In presence of DO (Fig. 3a), during $\gamma$ radiolysis thiacloprid concentration decreased linearly with the time (dose, slope $1.9 \times 10^{-7} \mathrm{~mol} \mathrm{~L}^{-1} \mathrm{~J}^{-1}$ ). The amount of thiacloprid transformed is lower by $\sim 30 \%$ than the yield of $\bullet \mathrm{OH} G$ $(\bullet \mathrm{OH})=2.8 \times 10^{-7} \mathrm{~mol} \mathrm{~J}^{-1}$, so the efficiency is around $70 \%$. This efficiency is much lower when it is calculated from the decrease of the $242 \mathrm{~nm}$ absorbance observed in the UV spectroscopic studies (Fig. $\mathrm{S} 1 \mathrm{e}$ ). When the sample was irradiated with an absorbed dose of 0.1 $\mathrm{kGy}$, the absorbance decreased only by $3 \%$.

It means that $\sim 10 \%$ of the $\bullet \mathrm{OH}$ induces the degradation of the chromofor. So the majority of the first transformations leave the chromofor intact. The linear time (dose) dependence, should be due to the lower reaction rate of the degradation initiating radicals with the products than with the starting molecules. Above $\sim 80 \%$ conversion the transformation rate becomes slower which is certainly due to the large concentration of the accumulated intermediates (Fig. 4e). At higher intermediate concentration there is a real competition between the starting compound and the intermediates for the reactive radicals. In presence of $\mathrm{DO}$, this competition is more evident in the cases of photocatalysis and VUV photolysis than in $\gamma$ radiolysis (Fig. 3a).

Fig. 4 shows the relative absorbances at 242 and $270 \mathrm{~nm}$ (the characteristic absorbance of the aromatic systems). In the presence of DO the absorbance at $242 \mathrm{~nm}$ does not change parallel with the thiacloprid concentration (Fig. $4 a, c$ and e), confirming the fact that the reactive species do not react only with the chromophore or the formed intermediates also absorb at this wavelength. The absorbances at $270 \mathrm{~nm}$ change similarly to those at $242 \mathrm{~nm}$, except in case of heterogeneous photocatalysis, where it follows the thiacloprid concentration. In this case the opening of the aromatic ring has the highest probability, thus accumulation of aromatic products can be avoided. In absence of DO the accumulation of the intermediates observed at both 242 and $270 \mathrm{~nm}$ is much higher (Fig. 4b, d and $\mathrm{f}$ ).

\subsection{Intermediates}

For the characterization of the intermediates, the samples that have been taken at irradiation times (or dose) of $50 \%$ conversion of thiacloprid, namely 15 and $150 \mathrm{~min} ; 5$ and $10 \mathrm{~min} ; 0.4$ and $0.3 \mathrm{kGy}$ in case of heterogeneous photocatalysis, VUV photolysis and $\gamma$ radiolysis in the presence and absence of DO, respectively, were analysed by HPLC-MS in positive and negative ion modes (Tables S1-S4).

In the chromatographic separations thiacloprid eluted with a retention time $\left(t_{\mathrm{r}}\right)$ of $4.58 \mathrm{~min}$. Three main intermediates (two with $t_{\mathrm{r}}=2.13-2.33 \mathrm{~min}$ and one with $3.65 \mathrm{~min}$, Fig. $5 \mathrm{a}-\mathrm{c}$ ) and the Eisomer of thiaclopid ( $t_{\mathrm{r}}=4.40 \mathrm{~min}$, Fig. $5 \mathrm{~d}$ ) were detected during all three methods. The MS-spectra (negative ion mode) and the UV-vis spectra of the Z- and E-isomers, having different retention times were found to be identical.

The retention time related to the chromatographic peak of intermediates A1 and A2 was between 2.13 and $2.33 \mathrm{~min}$. As the UV-vis spectra of these peaks (Fig. 5a and b) show, this is the mixture of two compounds, which cannot be separated by the applied chromatographic method. According to the spectra, during VUV photolysis (both in DO-free and DO-containing solutions) and heterogeneous photocatalysis (only in DO-containing suspension) the same intermediate $\left(A_{1}\right)$ forms. The formation of this compound is most likely related to the ${ }^{\bullet} \mathrm{OH}$-based reaction, which is the dominant reactive species under these experimental conditions. However, in case of radiolysis the formation of $\mathrm{e}_{\mathrm{aq}}{ }^{-}$is also dominant. Regarding that the reactivity of pyridine (part of thiacloprid) toward $\mathrm{e}_{\mathrm{aq}}{ }^{-}$overtakes its reactivity toward ${ }^{\bullet} \mathrm{OH}$ [27], in this case the transformation of thiachloprid can be initiated by both the ${ }^{\circ} \mathrm{OH}$ and $\mathrm{e}_{\mathrm{aq}}{ }^{-}$, resulting in the possibility of the formation of different intermediates $\left(A_{1}\right.$ and $A_{2}$ ). According to our results $A_{2}$ formation is dominant under the used experimental conditions. In the case of heterogeneous photocatalysis, in DO-free suspension the direct charge transfer between the adsorbed thiacloprid and photogenerated $\mathrm{e}^{-}$is also possible and results the formation of $\mathrm{A}_{2}$. Consequently, the same intermediate forms as during $\gamma$ radiolysis. The spectra of this compound (Fig. 5b) are background corrected, due to the incomplete chromatographic separation from the other intermediate and their overlapping absorptions in this wavelength range. The results of MS (Table S1) support the formation of two intermediates having retention times close to each other. $A_{1}$ and $A_{2}$ intermediates do not contain chlorine atom. We identify $\mathrm{A} 1$ as an intermediate resulted by the substitution of $\mathrm{Cl}$ by $\mathrm{OH}$, which is frequently observed in the - OH reactions of chlorinated aromatic molecules.

The other major intermediate detected at $3.65 \mathrm{~min}$ (intermediate B) formed in each case, with different concentrations (Figs. 5 c and $6 \mathrm{c}$ ). The concentration of this intermediate decreased in the following order: radiolysis (DO-free) $\cong$ radiolysis (DO) $>$ VUV (DOfree) $>$ VUV (DO) " heterogeneous photocatalysis (DO) and detected only in trace in the case of heterogeneous photocatalysis (DO-free). MS results (Table S1) support that the same intermediate formed in each case. The intermediate B most probably resulted from thiacloprid via hydroxylation. In $\bullet \mathrm{OH}$-induced reaction Dell'Arciprete et al. suggested the formation of a compound hydroxylated on the 
a)

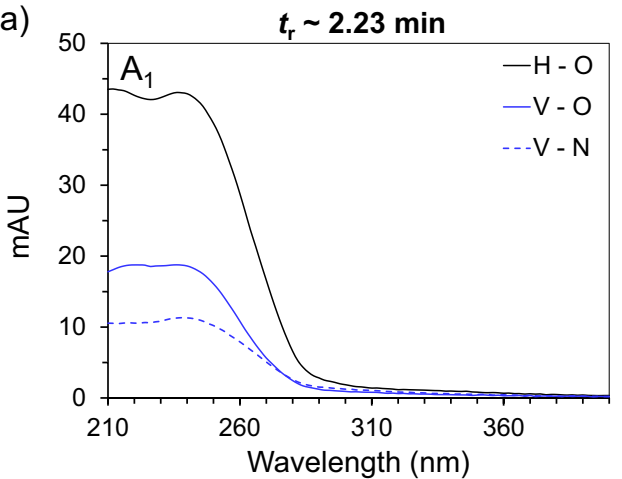

c)

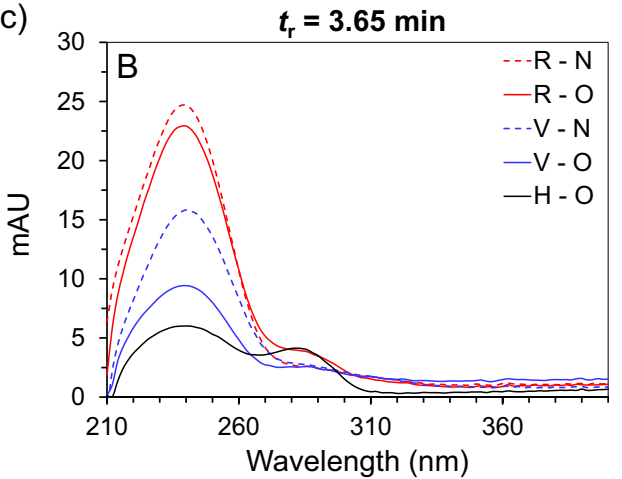

b)

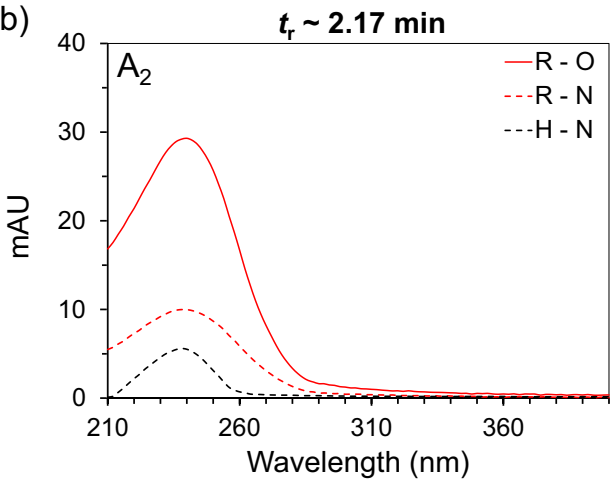

d)

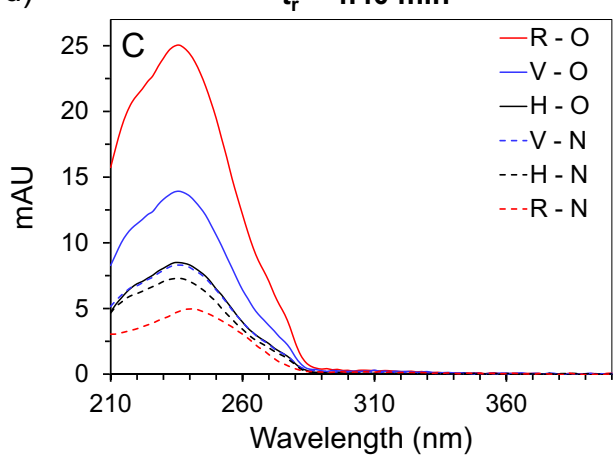

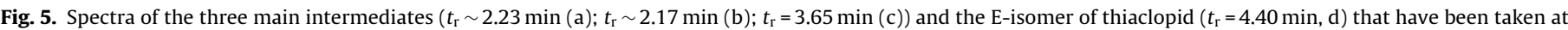

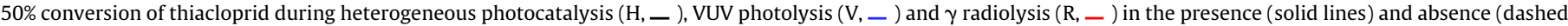
lines) of dissolved $\mathrm{O}_{2}$.

$\mathrm{CH}_{2}$ group [30], whereas Cernigoj et al. reported the formation of the sulfoxide compound as a result of thermal oxidation [15].

\subsection{Electric energy per order $\left(\mathrm{E}_{E O}\right)$}

The comparison of the methods is generally based on the transformation rate of the target substance or total organic carbon concentration. In the present work various methods and experimental parameters were applied. $E_{\mathrm{EO}}$, which is usually applied for situations where initial concentration of pollutant is low, gives possibility for economic comparison. It represents the amount of electric energy required for reduction of the target compound concentration in a unit volume [e.g., $1 \mathrm{~m}^{3}$ ] by one order of magnitude [34]. In batch operation $E_{\mathrm{EO}}$ values [ $\mathrm{kWh} \mathrm{m}^{-3}$ order $^{-1}$ ] can be calculated using Eq. 10.

$E_{E O}=\frac{P \times t \times 1000}{V \times \lg \left(c_{i} / c_{f}\right)}$

where $P$ is the rated power [ $\mathrm{kW}]$ of the AOP system, $V$ is the volume [L] of water or air treated in the time $t[\mathrm{~h}], c_{i}, c_{f}$ are the initial and final concentrations $\left[\mathrm{mol} \mathrm{L}^{-1}\right]$ of the target compound. Factor 1000 converts $\mathrm{L}$ to $\mathrm{m}^{3}$. Higher $E_{\mathrm{EO}}$ values correspond to lower removal efficiencies.

Calculated data are presented in Table 1 and show that the economically most feasible is $\gamma$ radiolysis, followed by VUV photolysis and heterogeneous photocatalysis. Another observation can be made from the ratio of the $E_{\mathrm{EO}}$ calculated at different initial concentrations showing, that it has no effect on the efficiency in case of heterogeneous photocatalysis, while in case of the other two methods it increases strongly with the decrease of the initial concentration.

\section{Conclusions}

Transformation of thiacloprid was compared using $\mathrm{TiO}_{2}$-based heterogeneous photocatalysis, VUV photolysis and $\gamma$ radiolysis, in presence and absence of DO. DO has significant effect only in case of heterogeneous photocatalysis. In aqueous solutions the transformation of thiaclropid is most probably related to reactions with both ${ }^{\bullet} \mathrm{OH}$ and $\mathrm{e}_{\mathrm{aq}}{ }^{-}$. In $\mathrm{TiO}_{2}$-containing suspensions reactions with - $\mathrm{OH}$ or direct charge transfer with photogenerated $\mathrm{e}^{-}$can initiate the transformation. Three main intermediates were detected in each case. The formation of intermediates $A_{1}$ and $B$ could be related to the ${ }^{\bullet} \mathrm{OH}$-initiated transformation, while the formation of $\mathrm{A}_{2}$ is most probably related to the reaction of thiacloprid with $\mathrm{e}_{\mathrm{aq}}{ }^{-}$ or photogenerated $\mathrm{e}^{-}$. Thiacloprid transformed with the highest initial reaction rate during VUV photolysis, however regarding the transformation of the intermediate products heterogeneous photocatalysis (in the present of DO) was more efficient.

Calculated $E_{\mathrm{EO}}$ data show, that $\gamma$ radiolysis is energetically much more feasible than VUV photolysis and heterogeneous photocatalysis.

\section{Acknowledgements}

The authors wish to express their deepest and sincerest recognition of Prof. András Dombi a key figure in the topic of photocatalytic materials for the degradation of contaminants of environmental concern.

This research was supported by OTKA, NK 105802. T. Alapi acknowledges the support of the European Union and the State of Hungary, co-financed by the European Social Fund in the framework of TÁMOP-4.2.4. A/2-11/1-2012-0001 'National Excellence Program'. K. Schrantz acknowledges the European Union and the State of Hungary, co-financed by the European Social Fund in the framework of TÁMOP 4.2.4. A/1-11-1-2012-0001'National Excel- 
a)

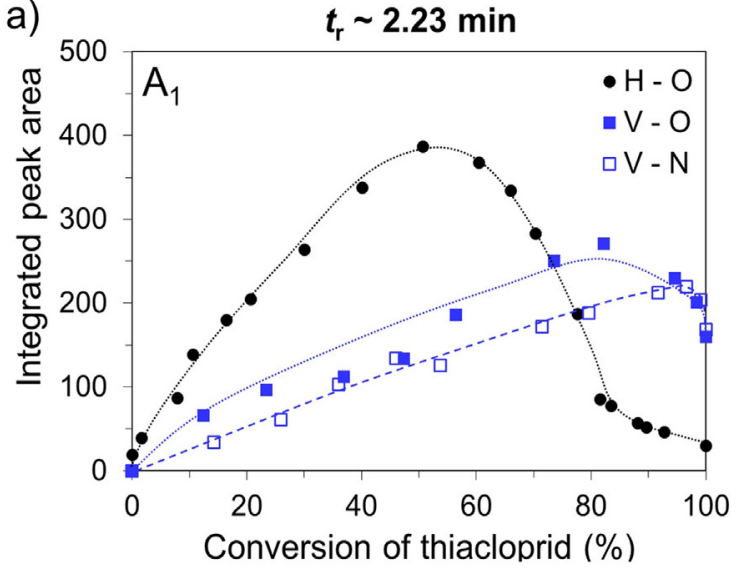

c)

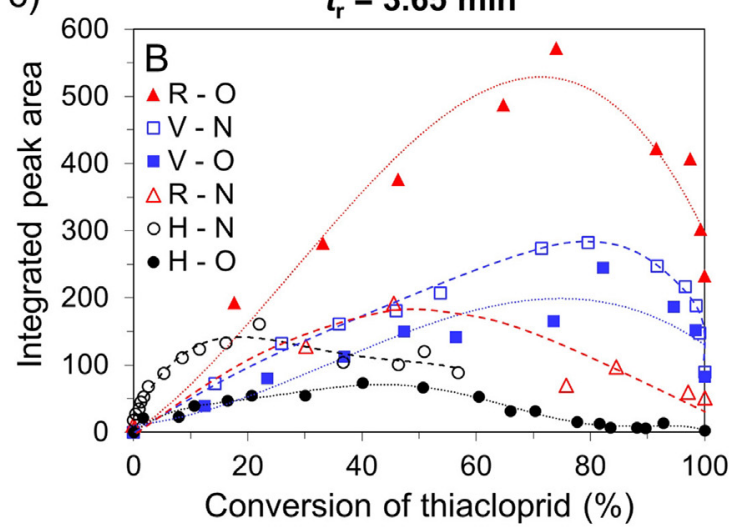

b)

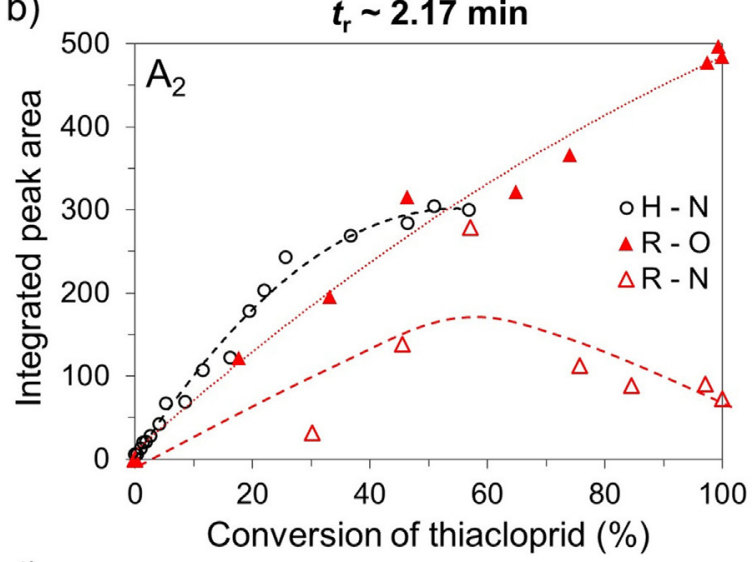

d)

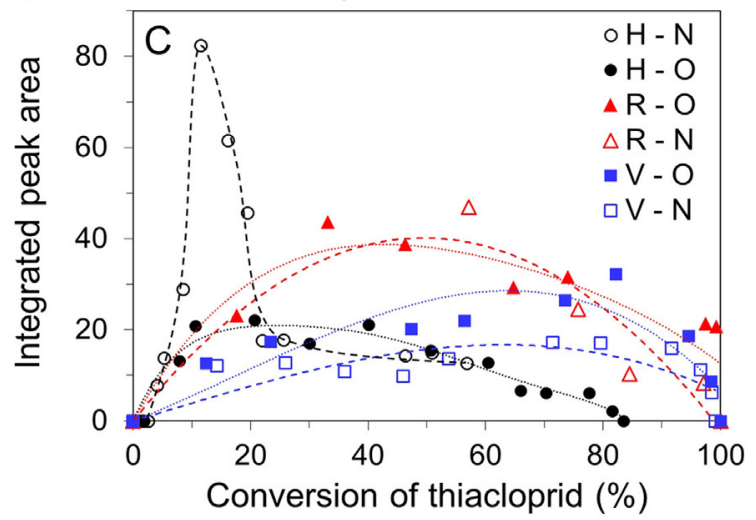

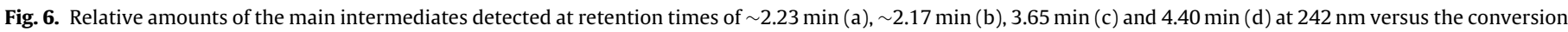

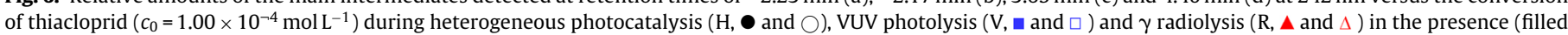
symbols) and in the absence (empty symbols) of dissolved $\mathrm{O}_{2}$.

lence Program'. The support of the Swiss Contribution (SH7/2/20) is also acknowledged.

\section{Appendix A. Supplementary data}

Supplementary data associated with this article can be found, in the online version, at http://dx.doi.org/10.1016/j.cattod.2016.11. 055.

\section{References}

[1] F. Sánchez-Bayo, R.V. Hyne, Detection and analysis of neonicotinoids in river waters-development of a passive sampler for three commonly used insecticides, Chemosphere 99 (2014) 143-151.

[2] N. Bacandritsos, A. Granato, G. Budge, I. Papanastasiou, E. Roinioti, M. Caldon, C. Falcaro, A. Gallina, F. Mutinelli, Sudden deaths and colony population decline in Greek honey bee colonies, J. Invertebr. Pathol. 105 (2010) 335-340.

[3] P. Jeschke, R. Nauen, M. Schindler, A. Elbert, Overview of the status and globa strategy for neonicotinoids, J. Agric. Food Chem. 59 (2011) 2897-2908.

[4] C.A. Morrissey, P. Mineau, J.H. Devries, F. Sanchez-Bayo, M. Liess, M.C. Cavallaro, K. Liber, Neonicotinoid contamination of global surface waters and associated risk to aquatic invertebrates: a review, Environ. Int. 74 (2015) 291-303.

[5] M. Arias-Estévez, E. López-Periago, E. Martínez-Carballo, J. Simal-Gándara, J.-C. Mejuto, L. García-Río, The mobility and degradation of pesticides in soils and the pollution of groundwater resources, Agric. Ecosyst. Environ. 123 (2008) 247-260.

[6] K. Paranjape, V. Gowariker, V.N. Krishnamurthy, S. Gowariker, The Pesticide Encyclopedia, CAB International, Boston,USA, 2014.

[7] V. Guzsvány, J. Csanádi, F. Gaál, NMR study of the influence of pH on the persistence of some neonicotinoids in water, Acta Chim. Slov. 53 (2006) 52-57.

[8] M. Pera-Titus, V. Garcí́a-Molina, M.A. Baños, J. Giménez, S. Esplugas, Degradation of chlorophenols by means of advanced oxidation processes: a general review, Appl. Catal. B: Environ. 47 (2004) 219-256.
[9] J. Zbiljić, V. Guzsvány, O. Vajdle, B. Prlina, J. Agbaba, B. Dalmacija, Z. Kónya, K. Kalcher, Determination of $\mathrm{H}_{2} \mathrm{O}_{2}$ by $\mathrm{MnO}_{2}$ modified screen printed carbon electrode during Fenton and visible light-assisted photo-Fenton based removal of acetamiprid from water, J. Electroanal. Chem. 755 (2015) 77-86.

[10] P.N. Patil, S.D. Bote, P.R. Gogate, Degradation of imidacloprid using combined advanced oxidation processes based on hydrodynamic cavitation, Ultrason. Sonochem. 21 (2014) 1770-1777.

[11] S. Malato, J. Blanco, J. Cáceres, A.R. Fernández-Alba, A. Agüera, A. Rodríguez, Photocatalytic treatment of water-soluble pesticides by photo-Fenton and $\mathrm{TiO}_{2}$ using solar energy, Catal. Today 76 (2002) 209-220.

[12] R. Zabar, T. Komel, J. Fabjan, M.B. Kralj, P. Trebse, Photocatalytic degradation with immobilised $\mathrm{TiO}_{2}$ of three selected neonicotinoid insecticides: imidacloprid, thiamethoxam and clothianidin, Chemosphere 89 (2012) 293-301.

[13] D Šojić, V Despotović, D. Orčić, E Szabó, E. Arany S. Armaković, E Illés, K Gajda-Schrantz, A. Dombi, T. Alapi, E. Sajben-Nagy, A. Palágyi, C. Vágvölgyi, L. Manczinger, L. Bjelica, B. Abramović, Degradation of thiamethoxam and metoprolol by $\mathrm{UV}, \mathrm{O}_{3}$ and $\mathrm{UV} / \mathrm{O}_{3}$ hybrid processes: kinetics, degradation intermediates and toxicity, J. Hydrol. 472-473 (2012) 314-327.

[14] U. Cernigoj, U.L. Stangar, J. Jirkovsky, Effect of dissolved ozone or ferric ions on photodegradation of thiacloprid in presence of different $\mathrm{TiO}_{2}$ catalysts, J. Hazard. Mater. 177 (2010) 399-406.

[15] U. Černigoj, U.L. Štangar, P. Trebše, Degradation of neonicotinoid insecticides by different advanced oxidation processes and studying the effect of ozone on $\mathrm{TiO}_{2}$ photocatalysis, Appl. Catal. B: Environ. 75 (2007) 229-238.

[16] N. Banić, B. Abramović, J. Krstić, D. Šojić, D. Lončarević, Z. Cherkezova-Zheleva, V. Guzsvány, Photodegradation of thiacloprid using $\mathrm{Fe} / \mathrm{TiO}_{2}$ as a heterogeneous photo-Fenton catalyst, Appl. Catal. B: Environ. 107 (2011) 363-371.

[17] N. Miranda-García, M.I. Maldonado, J.M. Coronado, S. Malato, Degradation study of 15 emerging contaminants at low concentration by immobilized $\mathrm{TiO}_{2}$ in a pilot plant, Catal. Today 151 (2010) 107-113.

[18] Y. Nosaka, A.Y. Nosaka, Identification and roles of the active species generated on various photocatalysts, in: P. Pichat (Ed.), Photocatalysis and Water Purification: From Fundamentals to Recent Applications, Wiley-VCH Verlag GmbH \& Co. KGaA, 2013, pp. 3-24

[19] P. Pichat, Photocatalysis and Water Purification, from Fundamentals to Recent Applications, Wiley-VCH Verlag GmbH \& Co. KGaA, 2013. 
[20] B.H.J. Bielski, D.E. Cabelli, R.L. Arudi, A.B. Ross, Reactivity of $\mathrm{HO}_{2} / \mathrm{O}_{2}{ }^{-}$radicals in aqueous solution, J. Phys. Chem. Ref. Data 14 (1985) 1041.

[21] N. Getoff, G.O. Schenck, Primary products of liquid water photolysis at $1236 \AA$ $1470 \AA$ and 1849 Å, J. Photochem. Photobiol. A: Chem. 8 (1968) 167-178.

[22] G. Heit, A. Neuner, P.Y. Saugy, A.M. Braun, Vacuum-UV (172 nm) actinometry. The quantum yield of the photolysis of water, J. Phys. Chem. A 102 (1998) $5551-5561$.

[23] E.J. Hart, M. Anbar, The Hydrated Elecrton, Wiley-Interscience, New York, 1970.

[24] G.V. Buxton, The radiation chemistry of liquid water: principles and applications., in: A. Mozumder, Y. Hatano (Eds.), Charged Particle and Photon Interaction with Matter, Marcel Dekker, New York, 2004, pp. 331-365.

[25] J.W.T. Spinks, R.J. Woods, An Introduction to Radiation Chemistry, 3rd ed., New York, USA (1990).

[26] G.V. Buxton, C.L. Greenstock, W.P. Helman, A.B. Ross, Critical-review of rate constants for reactions of hydrated electrons, hydrogen-atoms and hydroxyl radicals $\left(\bullet^{\bullet} \mathrm{OH} /{ }^{\bullet} \mathrm{O}^{-}\right)$in aqueous-solution, J. Phys. Chem. Ref. Data $17(1988)$ 513-886.

[27] S. Solar, N. Getoff, K. Sehested, J. Holcman, Pulse radiolysis of pyridine and methylpyridines in aqueous solutions, Radiat. Phys. Chem. 41 (1993) 825-834.

[28] P. Neta, R.H. Schuler, Effect of ionic dissociation of organic compounds on their rate of reaction with hydrogen atoms, J. Phys. Chem. 76 (1972) 2673-2679.
[29] K. Kosno, I. Janik, M. Celuch, J. Mirkowski, J. Kisała, D. Pogocki, The role of pH in the mechanism of $\mathrm{OH}$ radical induced oxidation of nicotine, Isr. J. Chem. 54 (2014) 302-315.

[30] M.L. Dell'Arciprete, L. Santos-Juanes, A.A. Sanz, R. Vicente, A.M. Amat, J.P. Furlong, D.O. Martire, M.C. Gonzalez, Reactivity of hydroxyl radicals with neonicotinoid insecticides: mechanism and changes in toxicity, Photochem. Photobiol. Sci. 8 (2009) 1016-1023.

[31] T. Oppenländer, R. Schwarzwälder, Vacuum-UV oxidation $\left(\mathrm{H}_{2} \mathrm{O}-\mathrm{VUV}\right)$ with a xenon excimer flow-through lamp at $172 \mathrm{~nm}$ : use of methanol as actinometer for VUV intensity measurement and as reference compound for OH-radical competition kinetics in aqueous systems, J. Adv. Oxid. Technol. 5 (2002) $155-163$.

[32] C.G. Hatchard, C.A. Parker, A new sensitive chemical actinometer. II. Potassium ferrioxalate as a standard chemical actinometer, Proc. R. Soc. A Math. Phys. Eng. Sci. 235 (1956) 518-536.

[33] L.G. Shevchuk, V.S. Zhikharev, N.A. Vysotskaya, Kinetics of the reactions of hydroxyl radicals with benzene and pyridine derivatives, J. Org. Chem. USSR 5 (1969) 1606-1608

[34] J.R. Bolton, K.G. Bircher, W. Tuman, C.A. Tolman, Figure-of-merit for the technical developement and application of advanced oxidation technologies for both electric- and solar-driven systems, Pure Appl. Chem. 73 (2001) 627-637. 